\section{Polymers for Advanced Applications}

\author{
20-23 November 2006, Stellenbosch, \\ South Africa
}

The 9th Annual UNESCO/IUPAC Conference on Macromolecules will be held from 20-23 November 2006 in Stellenbosch, South Africa. The conference will be centered around "Polymers for Advanced Applications." Four themes have been selected that will be covered in eight plenary lectures:

- hydrogels

- polymer brushes

- vesicles

- $\quad$ synthetic/biopolymer hybrids

Speakers who already have accepted invitations include K. Matyjaszewski (Carnegie Mellon University, Pittsburgh, USA), W. Hennink (Utrecht University, The Netherlands), S. Brocchini (Univ. London, UK), and $\mathrm{H}$. Maeda (Sojo University, Japan).
One of the above mentioned topics will be discussed per day. The morning session will largely be dedicated to synthesis and characterization of the materials. The focus of the afternoon session will be more on applications of the indicated classes of materials. However, there will be flexibility in the program to accommodate contributions in the field of "Polymers for Advanced Applications" that do not exactly fit in the indicated four areas.

The conference will be held in the town of Stellenbosch, which is located about 30 minutes from the airport of Cape Town. Stellenbosch is surrounded by mountains and is in the middle of the well-known wine district of South Africa. November is the beginning of the summer in South Africa, which means that the weather will be very pleasant.

See Mark Your Calendar on page 36 for contact information.

http://academic.sun.ac.za/unesco/Conferences/Conference2006/ HOMEPAGE2006.htm

\section{NanoTech Insight '07}

\section{0-17 March 2007, Luxor, Egypt}

The International Conference on Nanotechnology: Science and Application (NanoTech Insight '07) will be held 10-17 March 2007 in Luxor, Egypt. The time for small is now. The nanoscale challenges all we know and imagine knowing. From the smallest parts come a universe of discovery. As with every scientific leap, we need new ways of thinking and exploring the problems at hand. With creativity, dedication, and open minds, we can turn yesterday's nanotech "science fiction" into today's reality.

NanoTech Insight aims to stimulate a worldwide dialogue on the planned advancement of nanotechnology. Interdisciplinary communication is the foundation of nanoresearch. This conference promotes this by covering the main topics in nano from a wide range of disciplines. The idea is not to build generalists but rather to guide the specialists to effectively use their knowledge and expertise to enrich the nano research domain.

In addition to the breathtaking and inspirational environment that Egypt provides for social networking, NanoTech Insight provides the chance for students and educators from developing countries to learn and be inspired by the world's leading researchers. In addition, the conference will provide special financial support for attendees from developing nations. "Responsible nanotechnology" dialogue must include all global players to ensure the risks and benefits of the new technology are fully understood. The conference emphasizes applications of nanotechnology for sustainable development, with special sessions on nano ethics, environmental applications, and nanotechnology for industry.

Topics include:

- Bio-applications

- Fabrication

- Medical and Pharmaceutical Applications

- Nano Applications for Clean and Renewable Energy

- Nano Ethics / Environmental Impact

- Nanomaterials and Structures

- NanoTech For Industry

- NanoTechniques

- Optoelectronics and Photonics

- Simulation and Molecular Dynamics

- Single Molecules

Sin. www.nanoinsight.net 